Western University

Scholarship@Western

$11-2018$

\title{
Improving Online Interactions: Lessons from an Online Anatomy Course with a Laboratory for Undergraduate Students
}

Stephanie M. Attardi

Western University

Michele L. Barbeau

Western University

Kem A. Rogers

Western University

Follow this and additional works at: https://ir.lib.uwo.ca/anatomypub

Part of the Anatomy Commons, and the Cell and Developmental Biology Commons

Citation of this paper:

Attardi, Stephanie M.; Barbeau, Michele L.; and Rogers, Kem A., "Improving Online Interactions: Lessons from an Online Anatomy Course with a Laboratory for Undergraduate Students" (2018). Anatomy and Cell Biology Publications. 138.

https://ir.lib.uwo.ca/anatomypub/138 


\title{
Improving Online Interactions: Lessons from an Online Anatomy Course with a Laboratory for Undergraduate Students
}

\author{
Stefanie M. Attardi $\mathbb{D}^{1,},{ }^{1,2}$ Michele L. Barbeau, ${ }^{2}$ Kem A. Rogers ${ }^{2 *}$ \\ ${ }^{1}$ Department of Biomedical Sciences, Oakland University William Beaumont School of Medicine, \\ Rochester, Michigan \\ ${ }^{2}$ Department of Anatomy and Cell Biology, Schulich School of Medicine and Dentistry, \\ The University of Western Ontario, London, Ontario, Canada
}

\begin{abstract}
An online section of a face-to-face (F2F) undergraduate (bachelor's level) anatomy course with a prosection laboratory was offered in 2013-2014. Lectures for F2F students (353) were broadcast to online students (138) using Blackboard Collaborate (BBC) virtual classroom. Online laboratories were offered using BBC and three-dimensional (3D) anatomical computer models. This iteration of the course was modified from the previous year to improve online student-teacher and student-student interactions. Students were divided into laboratory groups that rotated through virtual breakout rooms, giving them the opportunity to interact with three instructors. The objectives were to assess student performance outcomes, perceptions of student-teacher and student-student interactions, methods of peer interaction, and helpfulness of the 3D computer models. Final grades were statistically identical between the online and F2F groups. There were strong, positive correlations between incoming grade average and final anatomy grade in both groups, suggesting prior academic performance, and not delivery format, predicts anatomy grades. Quantitative student perception surveys (273 F2F; 101 online) revealed that both groups agreed they were engaged by teachers, could interact socially with teachers and peers, and ask them questions in both the lecture and laboratory sessions, though agreement was significantly greater for the F2F students in most comparisons. The most common methods of peer communication were texting, Facebook, and meeting F2F. The perceived helpfulness of the 3D computer models improved from the previous year. While virtual breakout rooms can be used to adequately replace traditional prosection laboratories and improve interactions, they are not equivalent to F2F laboratories. Anat Sci Educ 11: 592-604. (c) 2018 American Association of Anatomists.
\end{abstract}

Key words: gross anatomy education; undergraduate education; online course; online lecture; online laboratory; distance education; computer-assisted instruction; online interaction

\footnotetext{
${ }^{*}$ Correspondence to: Dr. Kem Rogers, Department of Anatomy and Cell Biology, Schulich School of Medicine and Dentistry, The University of Western Ontario, London, Ontario N6A 5C1, Canada. E-mail: Kem.Rogers@schulich.uwo.ca

Additional Supporting Information may be found in the online version of this article.

Received 7 August 2017; Revised 20 December 2017; Accepted 31 January 2018.

Published online 01 March 2018 in Wiley Online Library (wileyonlinelibrary.com). DOI 10.1002/ase.1776
}

(c) 2018 American Association of Anatomists 
concomitant reduction in the necessity to rely on cadavers (Aziz et al., 2002). Novel approaches include diagnostic imaging (Aziz et al., 2002; Trelease, 2002; McLachlan et al., 2004; Gunderman and Wilson, 2005; Collins, 2008), digital images (Trelease, 2002), medical simulators (Trelease, 2002; McLachlan et al., 2004; Sugand et al., 2010), anatomical data sets (Spitzer et al., 1996), virtual reality (Trelease, 2002), and three dimensional (3D) anatomical computer models (Trelease, 2002, Sugand et al., 2010).

Computer-assisted instruction (CAI) tools have been incorporated into face-to-face (F2F) anatomy courses with the goal of facilitating student learning. "Face-to-face" describes the traditional teaching setting where instructors and students are present in the same physical space at the same time. Anatomy education researchers have documented the use of CAI tools for F2F students in the form of online discussion forums (Durham, et al., 2009; McNulty et al., 2009, Choudhury and Gouldsborough, 2012; Green and Hughes 2013; Green et al., 2014), anatomy e-learning modules (Green et al., 2006; Raynor and Iggulden, 2008), online anatomical illustrations (Durham et al., 2009), interactive photographs (O’Byrne et al., 2008; Doubleday et al., 2011; Guy et al., 2015), online lecture captures (Bacro et al., 2010; McNulty et al., 2011; Nieder and Borges, 2012; Bacro et al., 2013; Beale et al., 2014; Singh and Min, 2017) and 3D computer models (Durham et al., 2009; Tallitsch et al., 2012; Wright, 2012).

These computer-assisted instructional tools, coupled with computerized alternatives for the human cadaver, have made opportunities possible for the implementation of online distance studies courses in anatomy. Simonson et al. (2011) defined distance education as a format where individuals in the learning group are separated from each other, but interactive telecommunication systems are used to connect students and instructors with each other and with the learning resources. Online courses are forms of distance courses. In a fully online course, students are required to have access to a computer with internet connectivity, and they can participate in its entirety without having to attend any face-to-face sessions (Bates, 2005).

Internet-based learning has increased in popularity in the education of health professionals (Cook et al., 2008). Despite the number of fully online anatomy courses offered through North American institutions (CVU-UVC, 2016; Study.com, 2017), few have documented their approach in the literature. Boudinot and Martin (2001) used A.D.A.M. Interactive Anatomy software (ADAM, 2017) to build lessons for doctor of pharmacy students by combining the interactive anatomical illustrations with institutionally produced text. Limpach et al. (2008) provided doctor of pharmacy students with PowerPoint (Microsoft Corp., Redmond, WA) files and accompanying audio recordings of their lessons. Mathiowetz et al. (2016) described a new online section of a hybrid anatomy course for occupational therapy students. In their study, all students learned foundational content through online modules that included links to Acland's videos of human anatomy (Acland, 2013), musculoskeletal anatomy flash cards, interactive activities (e.g., click and drag, questions and answers), self-quizzes, and application assignments. All students attended F2F kinesiology laboratories and other interactive sessions focused on muscle palpation; however, to satisfy the anatomy laboratory component, the F2F students studied from prosections while online students studied from 3D anatomical computer models.
More recently in the United Kingdom, University of Leeds offered a massive open online course (MOOC) on abdominal anatomy (Swinnerton et al., 2017; Pickering and Swinnerton, 2017). The course materials included short videos of the instructors teaching using anatomical models, videos of handdrawn and animated images, screencasts, and interviews with clinicians to discuss clinical correlates. The course was used as a supplementary learning tool for medical students (Swinnerton et al., 2017) and as a professional development tool for healthcare workers (Pickering and Swinnerton, 2017).

In 2012, The University of Western Ontario offered a fully online section of a traditional F2F undergraduate (bachelor's level) systemic human anatomy course with a prosection laboratory using Blackboard Collaborate (BBC) 12 videoconferencing software (Blackboard Inc., Washington, DC) and Netter 3D Anatomy (Netter, 2014) computer models. This was the first description of an online anatomy course where teachers and students interacted live online while using 3D computer models (Attardi and Rogers, 2015). Assessments of student performance revealed no significant differences between delivery format and final anatomy grade (Attardi and Rogers, 2015). Incoming grade averages were positively and strongly related to final anatomy grades in both sections, indicating that previous academic performance, and not delivery format predicted success in the course (Attardi and Rogers, 2015). A study comparing perceptions of the learning experience in the online versus F2F format (Attardi et al., 2016) revealed that online students valued archived materials for the opportunity to control the instructional pace, attendance schedule, and their location. The F2F students were more engaged by their instructors in the traditional format for both the lecture and laboratory because it was easier to interact F2F. They also preferred the F2F laboratory because they had difficulty using the 3D computer models and valued the unique hands-on experience offered by cadaveric specimens. It was suggested that the online students should have the option to attend extra laboratory hours to study from cadaveric specimens and the F2F students have the option to study from archived materials. These findings, along with distance education theory, informed the modification of the online course for its second offering which is examined in this manuscript.

\section{Theoretical Framework}

Transactional distance is a pedagogical concept defined as a psychological space between the teacher and the learner in which there is a potential for misunderstanding (Moore, 1993). Transactional distance cannot be directly measured, as it is a relative and not an absolute term. Instead, educational methods can be described in terms of their effect on transactional distance. The concept of transactional distance can be applied to F2F learning systems, though it is most commonly discussed in terms of the distance education format since participants are separated physically from each other.

Moore (1993) defines two variables of which transactional distance is a function: the instructional dialogue and program structure. The term "dialogue" refers to purposeful interactions of a positive quality between teachers and students. The communication method directly impacts the quality of dialogue, and thus the transactional distance. For example, a lesson during which communication is unidirectional from the 
teacher to the student (e.g., via audiotape) will lack dialogue because the medium does not allow the learner to communicate back to the teacher. Through careful selection of communication methods that increase dialogue, the transactional distance is reduced. Moore identified other factors that affect dialogue such as the physical environment in which the participants are located, frequency and opportunity of communication, and the emotional status and personality of the participants.

Moore's (1993) "program structure" refers to the way that the educational experience is designed for delivery through communication media. Highly structured programs are those that employ inflexible instructional media, and the way that students use the media is predetermined. There is no opportunity for deviation from the lesson to suit the needs of a particular learner. For example, in a pre-recorded educational video, the words and activity of the instructor and time on task are fixed. There is no opportunity for the learner to influence the course of the lesson. Conversely, programs with a relatively open structure, in which personalized interactions can take place, allow the learner to determine the course of the lesson. Transactional distance decreases as the program become less structured.

Moore (1989) defined the different types of interactions that occur in a distance education course. Learner-content interaction refers to the process of interacting intellectually with the content, which results in changes of the learner's understanding of the material. The learning resources are intended to facilitate the learner's interaction with the content. Learner-instructor interaction refers to acts through which the expert motivates the student to learn and stimulates the student's interest. The interaction is not limited to the conventional conversation. The instructor may present information, demonstrate a skill, or model a specific attitude or value. A teacher's influence on student learning is greater when there are learner-instructor interactions compared to student-content interactions alone. The final type, learnerlearner interaction, occurs between students. Though its importance is often overlooked in undergraduate education, this interaction can be a valuable resource for learning. In this report the learner is referred to as the "student" and the instructor as the "teacher." Bernard et al. (2009) used Moore's (1989) interactions as a basis for their meta-analysis of 74 studies on distance education and reported a positive association between strong interactions and student achievement outcomes. Thus, the aim for the second offering of the online anatomy course was to increase interaction, increase dialogue, and continue to offer a flexible program structure.

\section{Objectives}

The aims of this study were to modify the online course based on student data from the inaugural year (Attardi and Rogers, 2015; Attardi et al., 2016) and Moore's distance education theories (Moore, 1989, 1993), and to reassess student outcomes. The specific research objectives were to: (1) Reassess whether prior academic performance and/or the modified course delivery format predict performance in anatomy. (2) Compare student perceptions of student-teacher communication, student-student communication and student engagement between the modified online and F2F sections. (3) Compare methods of student-student communication outside of scheduled class time between the modified online and F2F students, and determine whether online learning materials were shared between the sections. (4) Reassess the online students' perceived helpfulness of the $3 \mathrm{D}$ anatomy computer models.

\section{MATERIALS AND METHODS}

The research protocol was approved by the Office of Research Ethics at The University of Western Ontario (REB\# 102631 and 103359).

\section{Pedagogical Modifications}

Modifications were made to the online laboratory to increase student-teacher interaction and dialogue with the goals of improving communication and better facilitating student use of Netter 3D Anatomy (learner-content interaction). Laboratories were facilitated online by a team of 3 teaching assistants (TAs) using BBC's breakout room tool. Breakout rooms are videoconferencing spaces separated from the main virtual classroom, each with their own private audio, video, instant messaging, and presentation tools. Content for a given laboratory was divided into two shorter lessons (15 minutes) with a TA facilitating each, which ran simultaneously using the main room and one virtual breakout room (Fig. 1). Students were divided into two groups and rotated through the rooms. The TAs, who had moderator accounts, randomly assigned student participants into one of the rooms. The third TA was logged into both rooms to help participants address technical issues unrelated to course content. For an additional hour, the students regrouped into the main virtual classroom for further optional discussion with one of the TAs. This format allowed the students to learn in smaller groups and gave them the opportunity to interact with three different TAs in a

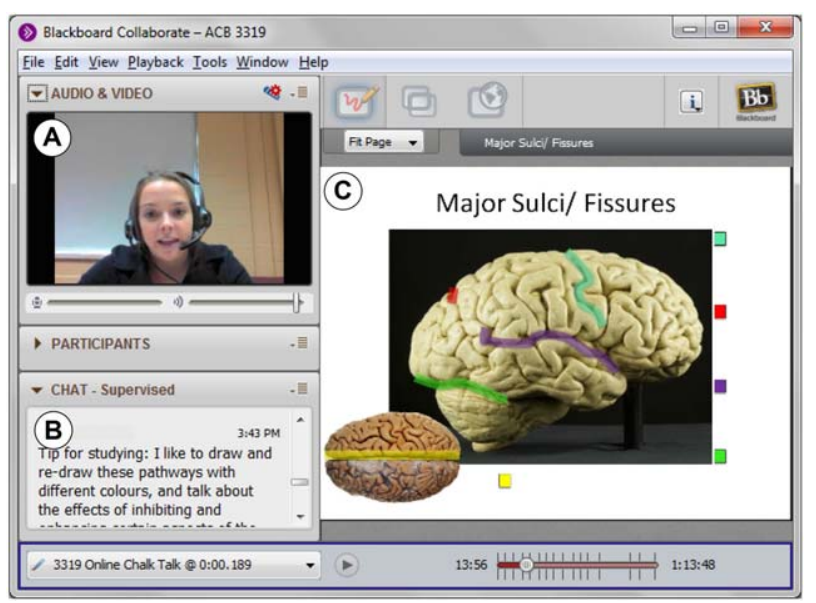

\section{Figure 1.}

Virtual breakout room. The content for each laboratory was divided into two smaller stations which ran simultaneously in two virtual classrooms with a teaching assistant (TA) facilitating each. Students could see and hear the TA (A) and communicate via instant messaging (B). A third TA was logged in to both rooms to help participants via instant messaging. The content area (C) displayed teaching aids with TA and student annotations added. Sample neuroanatomy image from Self-Directed Neuroanatomy Laboratory, University of Western Ontario, London, Canada (SDNL, 2012). 
laboratory session. Use of the third TA granted students prompt technical support during the laboratory without interruption of the lesson. Extra technical support was offered at the beginning of the course. One week prior to commencement of the laboratories, online students were trained on how to communicate in the virtual classroom, and how to use Netter 3D Anatomy and the 360anatomy rotatable brains (SDNL, 2012). A recording of each of the two small lessons was archived for future viewing by students.

To further increase student-content interaction, live manipulation of 3D models by the TA was replaced with PowerPoint slides. The TAs prepared slides of screen shots from key views of the $3 \mathrm{D}$ models. The slides were not intended to replace $3 \mathrm{D}$ model use, rather to function as a teaching aid for orienting students to what they should focus on when using the models independently to study. Using PowerPoint slides allowed the TAs and students to add markings to the slides using free form drawing tools and encouraged the students to study the models independently.

Voluntary F2F laboratory time (1 hour/week) was offered to online students as per the suggestion from former students (Attardi et al., 2016), TAs, and professors. The regular F2F laboratory sessions were held on the same weekday for the whole day with the exception of a 1-hour lunch break for the TAs. The optional laboratory time for online students was scheduled during the lunch break, taking advantage of the facility's set up for anatomy sessions. Online students could use cadaveric prosections and plastic models for independent study. The course coordinator and a former undergraduate anatomy student volunteer were present at these sessions to supervise and answer questions, but did not provide formal instruction. Students did not need to enroll in advance and could attend the sessions on a drop-in basis. Laboratory test review sessions were offered to both online and F2F students several days prior to each laboratory test for 3 hours. Students had the opportunity to see the prosections which had been used for that block of material, and several TAs were present to answer questions.

Student comprehension of lecture material continued to be evaluated by 4 quarterly multiple choice tests, although their total contribution to the final grade decreased from $90 \%$ to $80 \%$. Weekly laboratory quizzes were replaced by quarterly fill-in-the-blank laboratory tests totaling $20 \%$ of the final grade. Laboratory test questions (30) were photographs and illustrations projected on a screen and students were required to identify structures or state functions. Each term lecture test and the corresponding laboratory test were administered F2F in a proctored setting and students from both course sections were subjected to the same conditions.

Lecture and laboratory recordings were not provided to F2F students in the second offering of the course for several reasons. The implementation of Blackboard Collaborate for lecture capture requires assistance from the institution's information technology (IT) personnel and the purchase of licenses for individual students. Since this was only the second offering of the course, having fewer students with access to the software ensured that timely technical support was available to those with access. Additionally, the institution may consult research on the software when considering expansion of the student licensees for future years. Segregation of the learning resources between the course sections was necessary to create an opportunity for research on online student perception of learning from archived material versus those attending F2F sessions, and to determine whether online students shared access to the recordings with F2F students.

\section{Assessment Measures and Data Analyses}

Descriptive and inferential statistics for student grades and survey responses were calculated using the Statistical Package for Social Sciences, version 22 (IBM Corp., Armonk, NY).

Academic performance. The technical support staff for the course and the Bachelor of Medical Sciences Administrative Office provided anonymous student grades. Assessments of student performance were compared between the sections using a Mann-Whitney $U$ test since the data were not normally distributed. Incoming grade averages were calculated for each student from second year required sciences courses (cell biology, biochemistry, genetics, organic chemistry, scientific methods, and statistics) since this subsection of courses was common to all anatomy students. A Pearson correlation test determined whether incoming grade averages and final anatomy grades were correlative.

Student perception. Perceptions of learning anatomy in the two delivery formats were collected using a survey that consisted primarily of quantitative questions. The survey items were selected based on results from a mixed methods study of the inaugural online class (Attardi et al., 2016). In a study of this cohort (Attardi et al., 2016), a sample of the class provided qualitative interview data, which were used to create items on a quantitative survey for a larger sample of students. This methodology is known to strengthen a quantitative instrument and yield more meaningful results (Bunton, 2016). Items from the previous study (Attardi et al., 2016) were adapted for use in the present study. Different versions of the survey were distributed to the online and F2F groups (Supporting Information S1). The subject matter was the same and many items were identical, but not all questions were applicable to both groups. The survey consisted of five parts: (1) Demographic information, (2) Perceptions of the learning experience. Items pertained to student-teacher and student-student interactions for academic and social purposes, and engagement with the teachers. While other purposes of communication may exist, this study focused on the social and pedagogical forms since their importance was emphasized by the previous cohort's students (Attardi et al., 2016). For the purposes of this study, "social communication" pertained to interpersonal communications unrelated to the course, and the interpretation of the construct was at the discretion of the students. Online students were also asked to report their attendance habits in terms of participating during live times and/or accessing archives. (3) Use of computer-assisted learning resources or physical specimens. Online student users of Netter 3D anatomy rated the helpfulness of the software's functions, while non-adapters of the technology indicated their reasons for underuse. (4) Peer collaboration. Students could report the frequency of student-student communication methods, as well as disclose if and how there was sharing of online resources between the sections. (5) Final comments. Students could write comments about anything they wanted the researchers to know. The survey was available online through Fluid Surveys (Fluidsurveys, Ottawa, ON, Canada) for a two week period between the students' last anatomy class and final set of tests.

Non-parametric tests were selected to compare data between the groups because the scales in the survey were ordinal. Survey items pertaining to perceptions of student- 
teacher and student-student interaction that were identical between the online and F2F groups were compared using a Mann-Whitney U independent samples test. Survey items pertaining to perceptions of student-teacher and student-student interaction that were identical between the lecture and laboratory settings within the same group (online or F2F) were compared using a Wilcoxon related samples test. Effect size $(r)$ for all comparisons was calculated from the $z$ score $(z)$ and sample size $(n)$ where $r=z / \sqrt{ } n$.

Since a major focus of the study was person-person interactions, internal consistency between 19 items related to interactions was assessed using Cronbach's alpha (Supplementary File 1, items 5i-v, 7ii-vi, and 12i-ix). Validity of the survey could not be assessed mathematically because data were collected anonymously and not linked to additional observations. The following measures were taken to ensure student anonymity and the collection of honest feedback. Firstly, students were made aware that their participation in the study and responses could in no way influence their anatomy grades. Personal identifiers were not stored with response data. The course professors and teaching assistants did not know who participated in the study. Participant recruitment, survey administration, and analysis were completed by a researcher with no academic affiliation to the course (S.A.). Falsification of responses is more likely to occur on high-stakes assessments (Chan, 2009), so honest responses were encouraged by assuring the students that responses could not impact their grades negatively. Secondly, the researchers did not communicate desirable outcomes to the students (Chan, 2009). During the recruitment process, participants were informed that the overall goal of the study was to simply identify strengths and weaknesses of anatomy course. Finally, it was communicated to students that meeting these research goals would help the institution to improve the delivery of the anatomy course and other distance studies course in which the respondents might enroll. Many students would have had a vested personal interest in responding in an honest manner to improve their future learning experiences.

Responses to the final open-ended question were analyzed for content using NVivo for Mac 11.4.2 (QSR International, Melbourne, Australia). Codes are short phrases that can be assigned to a specific portion of language-based data to represent a specific attribute (Saldaña, 2016). The researchers created codes using the NVivo's "node" function and associated them with the appropriate highlighted sections of text to organize the data and report code occurrences.

\section{RESULTS}

Students self-selected their section during course registration, resulting in the enrollment of $353 \mathrm{~F} 2 \mathrm{~F}$ and 138 online students. Statistics on academic performance were calculated from the entire population, while the survey respondents were volunteers from both the online $(101 / 138 ; 73.2 \%$ participation rate) and F2F $(273 / 354 ; 77.1 \%$ participation rate) sections. Results for five-point Likert scale items were reported as mean \pm standard deviation. Effect sizes for significant differences between the sections were reported in the graphs (Figs. 3, 4, and 5) and ranged from mild $(r=0.12)$ to moderate $(r=0.58)$, but were not discussed for each comparison.

\section{Demographics}

The average age of the survey respondents was 20.85 years $(\mathrm{SD}=1.18)$. There were approximately the same number of males $(48.1 \%)$ compared to females $(51.6 \%)$. Most students $(68.6 \%)$ were in the Bachelor of Medical Sciences program. There was homogeneity between the sections in terms of mean age $(P=0.08)$, proportion of males to females $\left(X^{2}=0.99, P=0.32\right)$, and distribution of degree programs $\left(X^{2}=0.61, P=0.74\right)$. Thus, remaining data for all students were analyzed together and not stratified by demographics.

\section{Qualitative Data}

Qualitative data from the final open-ended question were provided by approximately half of the survey respondents $(51.4 \%$ online; $44.3 \% \mathrm{~F} 2 \mathrm{~F})$. Few codes were related to the survey data such that they could explain some of the quantitative outcomes for student performance and perceptions. Representative quotations were included where applicable with the results and were presented exactly as written by students. Most of the qualitative findings were unrelated to the study and more appropriate for course and instructor evaluations.

\section{Academic Performance}

The incoming grade average of the online students $(79.09 \%$, $\mathrm{SD}=9.15 \%$ ) was significantly higher (Mann-Whitney U Test, $P=0.01)$ than the F2F students $(76.75 \%, \mathrm{SD}=9.181)$. There were strong, positive correlations (Pearson) between incoming grade average and final anatomy grade in both the online $(r=0.70, P<0.01)$ and F2F $(r=0.71, P<0.01)$ sections (Fig. 2). On the first laboratory test, the online students' average $(72.77 \%, \mathrm{SD}=11.87)$ was significantly higher (MannWhitney U Test, $P<0.001)$ than the F2F students' $(67.67 \%$, $\mathrm{SD}=13.29$ ) (Table 1$)$. This difference did not translate into a difference in final anatomy grades (Table 1). There were no significant differences between group means on the remaining assessments. Survey comments from F2F students $(n=6)$ suggested that the group might not have felt prepared to see cadaveric images on the first laboratory test. For example, they explained "I don't think it was emphasized how well we needed to know how to identify structures, particularly in cadaveric images" and "I would have felt more prepared for the lab portion of the exams if there was a greater emphasis on cadaveric images in lab". Students in both sections mildly agreed, on the five-point Likert scale, that the laboratory demonstrations helped prepared them for the laboratory tests (3.24 \pm 1.17 online; $3.4 \pm 1.19 \mathrm{~F} 2 \mathrm{~F}$ ), and they agreed the lectures helped them to prepare for lecture tests $(4.20 \pm 0.93$ online; $4.07 \pm 0.95 \mathrm{~F} 2 \mathrm{~F})$.

\section{Online Student Attendance Methods}

A large majority of online student survey respondents $(81.2 \%)$ reported that they attended most of their lectures in archived format, few $(2 \%)$ logged in during live times, and a small group $(11.9 \%)$ attended some lectures live and some recorded. Some of the online students in the group that did not select any of the provided attendance options (5\%) commented that they attended the F2F lectures. The online students agreed that they valued having unlimited access to 

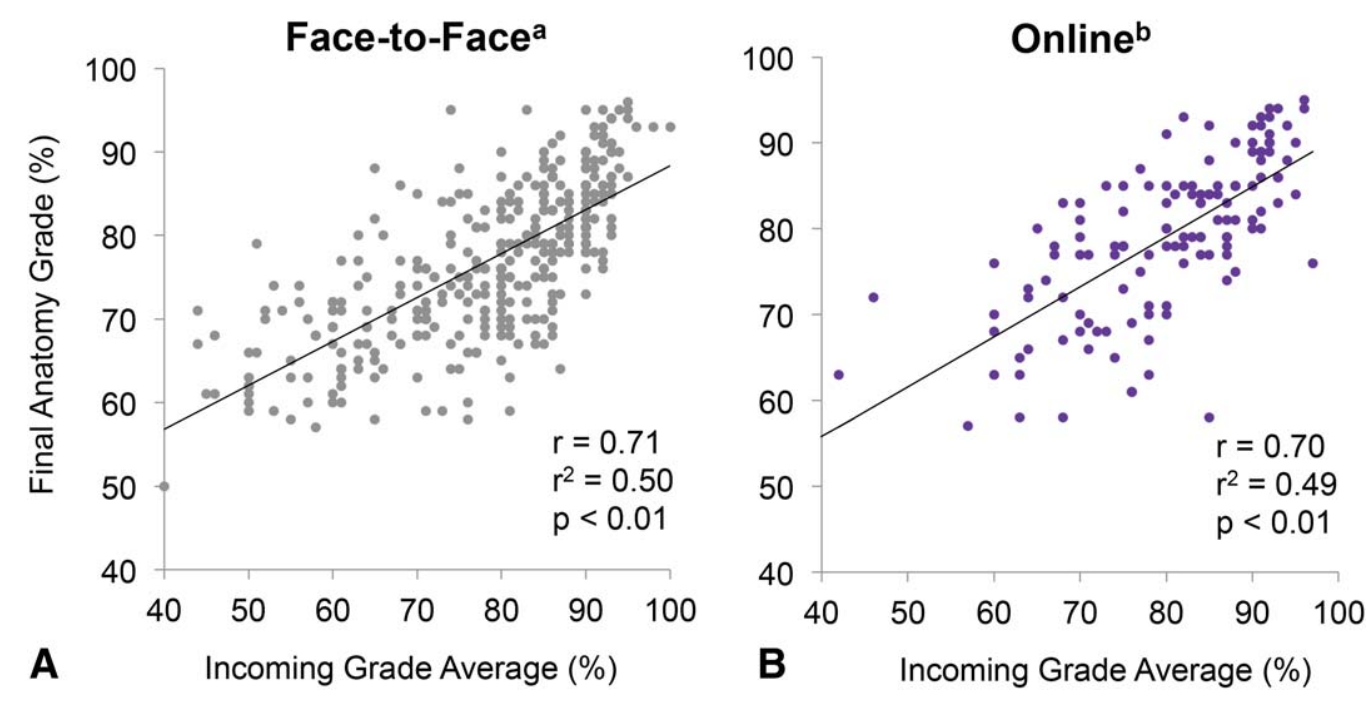

Figure 2.

Pearson's correlation between incoming grade average and final anatomy grade. There were strong, positive correlations between incoming grade average and final anatomy grade in both the face-to-face $(\mathbf{A})$ and online $(\mathbf{B})$ sections. ${ }^{\mathrm{a}} \mathrm{N}=354 ;{ }^{\mathrm{b}} \mathrm{N}=138$.

archives $(4.62 \pm 0.79)$ and the ability to control the pace of recordings $(4.69 \pm 0.91)$. Many F2F students $(n=28)$ and few online students $(n=3)$ commented that all students should have access to archived materials. One online student elaborated, "I loved the ability to re-listen to lectures as many lecturers spoke too quickly for me to get everything down the first time - this is a feature that I believe face-toface students should also be given access to, as it was incredibly helpful for me".

Online student reports of their laboratory attendance were similar to lecture attendance. A large majority (80.2\%) watched most of the laboratory demonstrations in archived format, a small group (10.9\%) attended some laboratories during live time and watched some as recordings, and few $(3 \%)$ attended during live time. The group who did not select any of the provided attendance formats $(5.9 \%)$ commented that they did not attend online laboratories in any format.

\section{Student-Teacher Interaction}

Responses to the 19 survey items relating to student-teacher and student-student interaction were found to be reliable $(\alpha=0.846)$, suggesting internal consistency for the items. On

\section{Table 1.}

Comparison of Student Performance Measures

\begin{tabular}{|c|c|c|c|}
\hline Assessment measure & Online students ${ }^{\mathrm{a}}$ mean grade $(\%) \pm \mathrm{SD}$ & Face-to-face students ${ }^{\mathrm{b}}$ mean grade $(\%) \pm \mathrm{SD}$ & $P$-value \\
\hline Lecture test 1 & $80.82 \pm 10.66$ & $78.87 \pm 11.59$ & 0.116 \\
\hline Lecture test 2 & $78.85 \pm 13.86$ & $77.25 \pm 13.19$ & 0.284 \\
\hline Lecture test 3 & $82.36 \pm 14.02$ & $81.48 \pm 14.92$ & 0.692 \\
\hline Laboratory test 3 & $63.52 \pm 18.98$ & $63.85 \pm 20.42$ & 0.666 \\
\hline Lecture test 4 & $79.65 \pm 12.25$ & $78.17 \pm 13.64$ & 0.365 \\
\hline
\end{tabular}

${ }^{\mathrm{a}} \mathrm{N}=138 ;{ }^{\mathrm{b}} \mathrm{N}=354 ;{ }^{\mathrm{c}}$ The online students scored significantly higher (Mann-Whitney $\mathrm{U}$ test) on Laboratory Test 1 compared to the face-to-face students. 
$\square$ Face-to-Face Students ${ }^{a}$

Online Students ${ }^{b}$
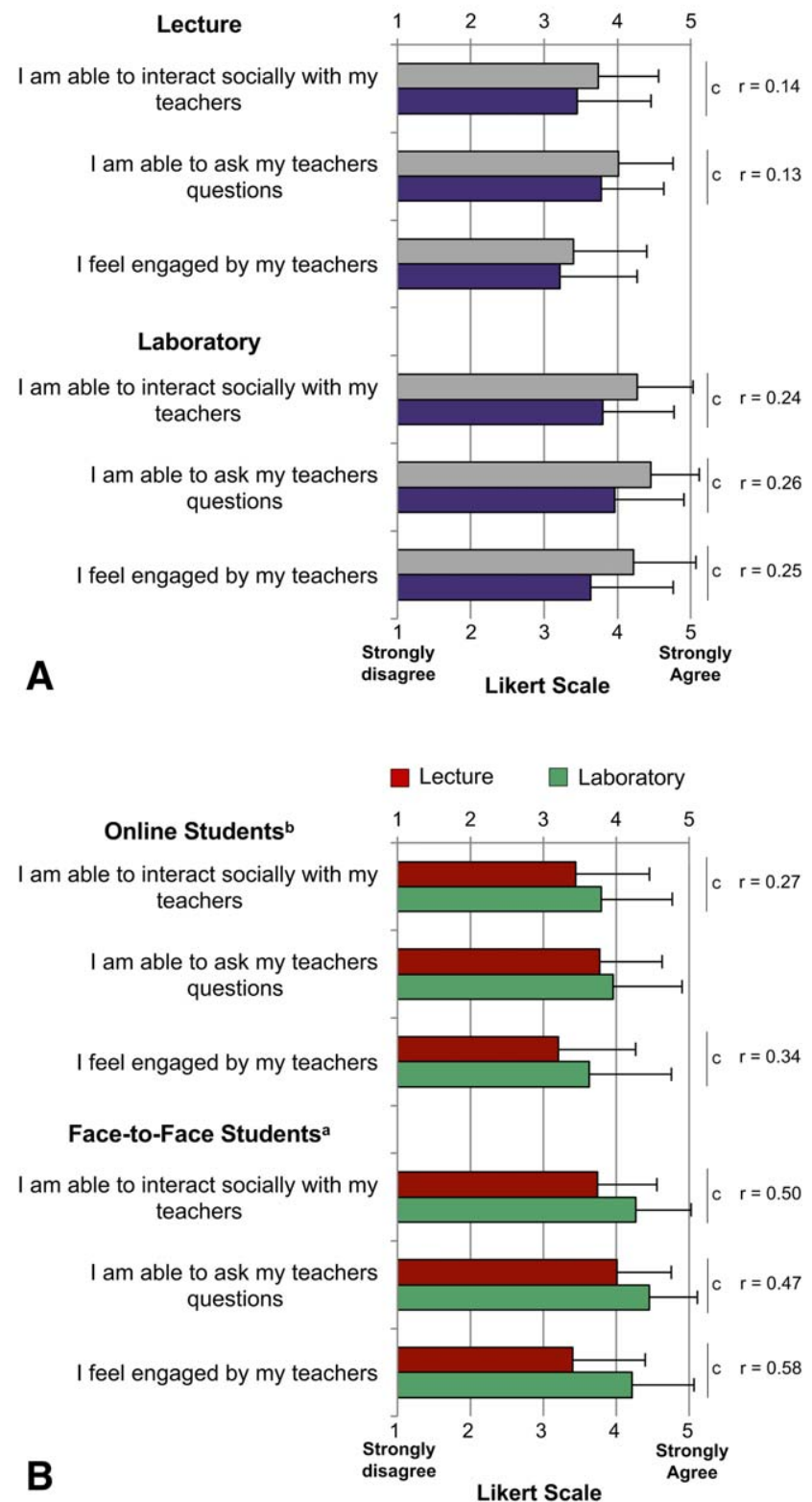

Figure 3.

Perceptions of student-teacher interaction reported as mean \pm SD. (A) Comparison between delivery formats within the lecture and laboratory settings; ${ }^{\mathrm{a}} \mathrm{N}=273 ;{ }^{\mathrm{b}} \mathrm{N}=101 ;{ }^{\mathrm{c}} \mathrm{P}<0.01$ Mann-Whitney $\mathrm{U}$ independent samples; effect sizes indicated by $r$. (B) Comparison between lecture and laboratory settings within delivery formats. ${ }^{\mathrm{a}} \mathrm{N}=273 ;{ }^{\mathrm{b}} \mathrm{N}=101 ;{ }^{\mathrm{c}} \mathrm{P}<0.01$ Wilcoxon related samples; effect sizes indicated by $r$.

average, most students in both sections agreed, using a five-point Likert scale, that they were able to interact socially with the professor $(3.74 \pm 0.82 \mathrm{~F} 2 \mathrm{~F} ; 3.45 \pm 1.01$ online) and ask questions (4.01 \pm 0.75 F2F; $3.78 \pm 0.52$ online) (Fig. 3A). A significantly greater number of F2F students agreed with these statements compared to online $(P<0.05$, Mann-Whitney $U$ independent samples). In both sections, on average, students neither agreed nor disagreed that they were engaged by the professor in the lecture setting (3.40 $\pm 1.00 \mathrm{~F} 2 \mathrm{~F} ; 3.21 \pm 1.06$ online), though the majority of students trended toward agreement. Students were asked to rate the same statements concerning their TAs in the laboratory setting. On average, most students in both sections agreed that they were able to ask the TA questions $(4.45 \pm 0.66 \mathrm{~F} 2 \mathrm{~F} ; 3.96 \pm 0.95$ online) and interact with the TA socially (4.27 $\pm 0.76 \mathrm{~F} 2 \mathrm{~F} ; 3.80 \pm 0.97$ online) (Fig. 3A). In both sections, students agreed that they were engaged by the $\mathrm{TA}$ in the laboratory setting $(4.22 \pm 0.85 \mathrm{~F} 2 \mathrm{~F}$; $3.63 \pm 1.13)$. A significantly greater number of F2F students agreed with these statements compared to online $(P<0.0001$, Mann-Whitney $\mathrm{U}$ independent samples). Furthermore, most online students agreed that it was easy for them to contact their TA regarding technical problems and have them resolved $(3.70 \pm 1.08)$.

Student-teacher communication was compared between the lecture (with the professor) and the laboratory (with the TA) within the same groups (online and F2F) (Fig. 3B). Significantly more online students agreed that they were engaged by the teacher and could interact with the teacher socially when in the laboratory setting compared to lecture $(P<0.01$, Wilcoxon related samples), suggesting that the TAs were able to better engage online students in the laboratory compared to the professors in lecture. Significantly more F2F students agreed that they were more engaged by teachers, could interact socially with teachers and ask them questions in the laboratory setting compared to lecture $(P<0.001$, Wilcoxon related samples) (Fig. 3B), suggesting that TAs were able to better engage F2F students and interact with them in the laboratory compared to the professors in lecture.

\section{Student-Student Interaction}

On average, students in both sections were able to ask their peers questions during a lecture $(4.04 \pm 0.83 \mathrm{~F} 2 \mathrm{~F} ; 3.64 \pm 0.94$ online) and interact socially to a lesser extent (3.83 \pm 0.91 F2F; $3.41 \pm 1.01$ online) (Fig. 4A). A significantly greater number of F2F students agreed with these statements compared to online $(P<0.001$, Mann-Whitney U independent samples).

Students were asked to rate the same statements concerning peer interaction in the laboratory setting. On average, most students in both sections agreed that they were able to ask their peers questions during a laboratory $(4.02 \pm 0.74$ F2F; $3.44 \pm 0.96$ online) and interact socially $(3.98 \pm 0.77$ F2F; $3.46 \pm 0.91$ ) (Fig. 4A). A significantly greater number of F2F students agreed with these statements compared to online $(P<0.001$, Mann-Whitney $\mathrm{U}$ independent samples).

Student-student communication was compared between the lecture and the laboratory within the same groups (online and F2F) (Fig. 4B). Significantly fewer online students agreed that they could ask their peers questions during the laboratory demonstration compared to lecture $(P=0.015$, Wilcoxon related samples). In contrast, a significantly greater number of F2F students agreed that they could interact socially with their peers in a laboratory setting compared to lecture $(P=0.005$, Wilcoxon related samples).

Methods of student-student communication. As seen in Figure 5, communication methods used most frequently by the students were Facebook (Facebook Inc., Menlo Park, CA) $(3.69 \pm 1.29 \mathrm{~F} 2 \mathrm{~F} ; 2.80 \pm 1.44$ online $)$, texting $(3.57 \pm 1.25$ F2F; $2.88 \pm 1.43$ online), and face-to-face meetings ( $3.44 \pm 1.20$ F2F; $2.84 \pm 1.40$ online). A significantly greater proportion of F2F students used these resources more frequently than the 


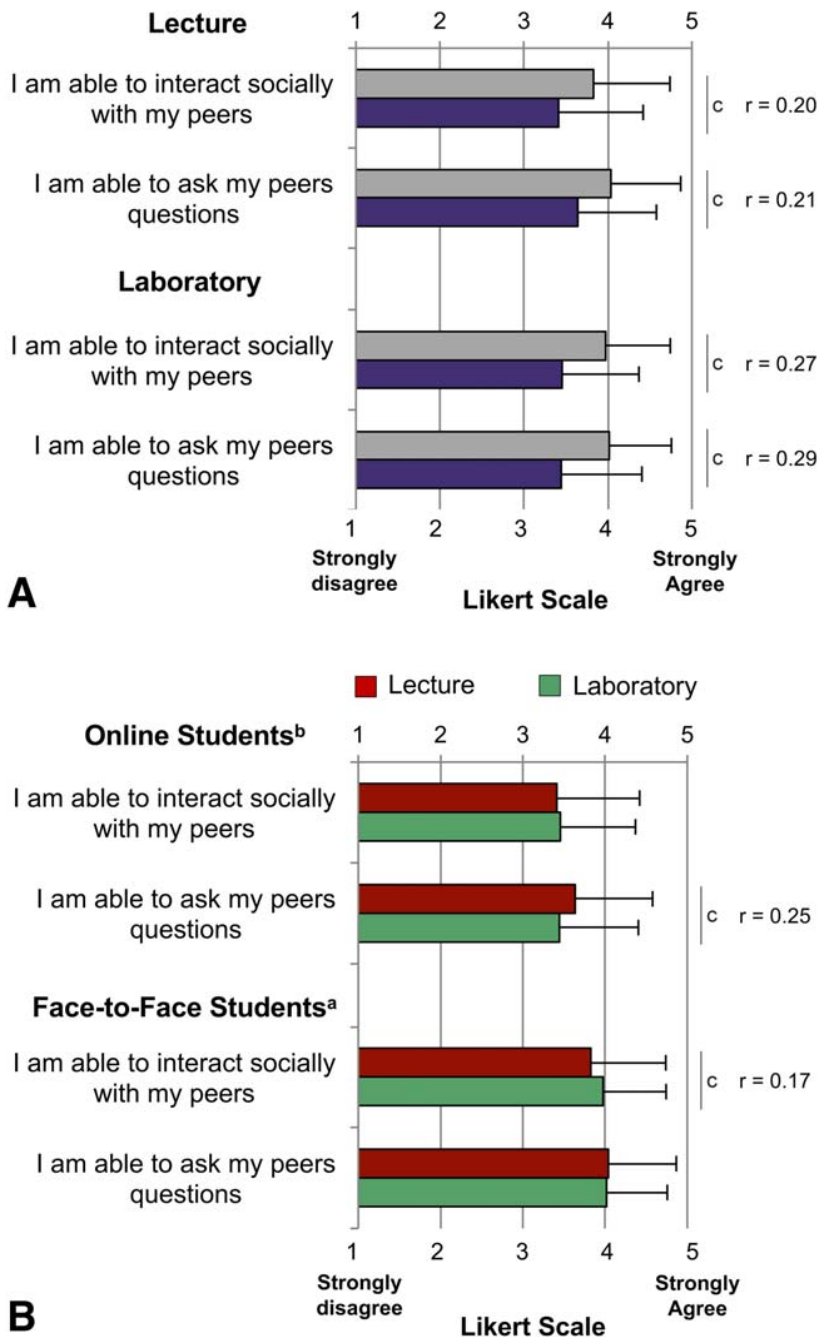

\section{Figure 4.}

Perceptions of student-student interaction reported as mean as \pm SD. (A) Comparison between delivery formats within the lecture and laboratory settings. ${ }^{\mathrm{a}} \mathrm{N}=273 ;{ }^{\mathrm{b}} \mathrm{N}=101 ;{ }^{\mathrm{c}} \mathrm{P}<0.01 \mathrm{Mann}$-Whitney $\mathrm{U}$ independent samples; effect sizes indicated by $r$. (B) Comparison between lecture and laboratory settings within delivery formats. ${ }^{\mathrm{a}} \mathrm{N}=273$; ${ }^{\mathrm{b}} \mathrm{N}=101$; ${ }^{\mathrm{c}} \mathrm{P}<0.01$ Wilcoxon related samples; effect sizes indicated by $r$.

online students $(P<0.01$, Mann-Whitney $\mathrm{U}$ independent samples). Interestingly, among the communication resources used infrequently was the forum in the learning management system (1.84 $\pm 1.00 \mathrm{~F} 2 \mathrm{~F} ; 1.55 \pm 0.81$ online).

Sharing of e-learning resources. A substantial number of online students $(25 ; 24.8 \%)$ reported that they shared their access to lecture and/or laboratory recordings with classmates in the F2F section. Within this group of students, the most common methods of providing access to archives were sharing login credentials for Blackboard Collaborate $(60 \%)$ and watching archives together $(24 \%)$. The least common methods were sharing access by providing a link to the recording $(4 \%)$ and other unknown methods $(8 \%)$. A few students $(12 \%)$ declined to respond to the question. Consequently, F2F students $(75 ; 27.5 \%)$ reported gaining access to archives,
Face-to-Face Students ${ }^{a} \square$ Online Students ${ }^{b}$

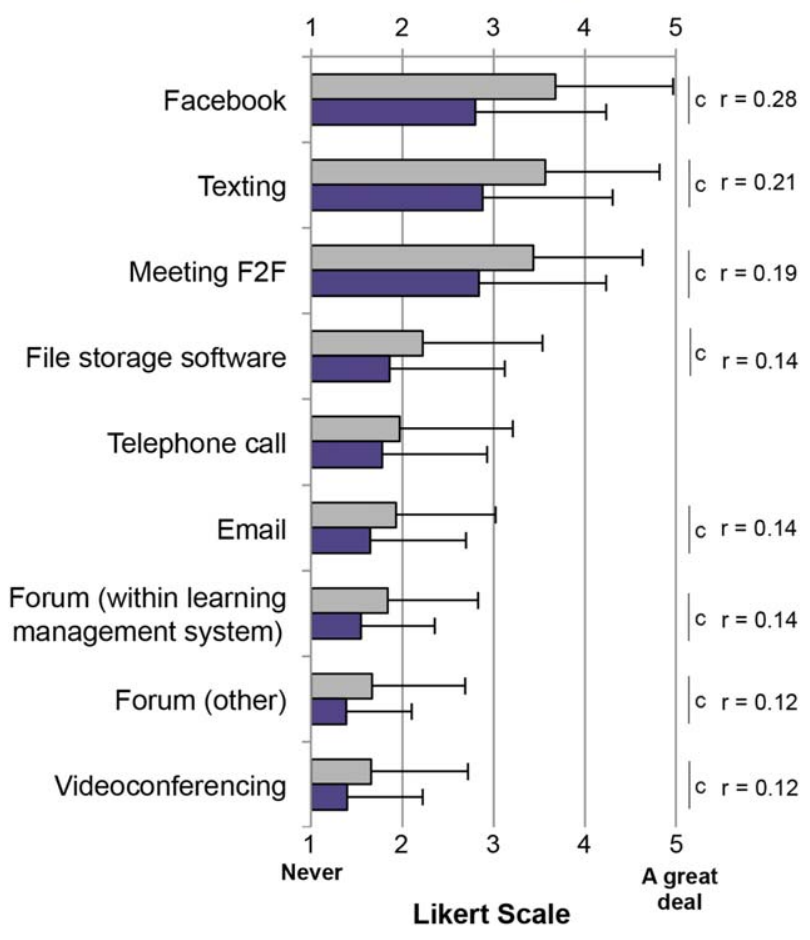

Figure 5.

Frequency of student-student communication methods pertaining to the study of anatomy reported as mean $\pm S D$. ${ }^{\mathrm{a}} N=273 ;{ }^{\mathrm{b}} N=101 ;{ }^{\mathrm{c}} P<0.01$ MannWhitney U independent samples; effect sizes indicated by r; F2F, face-to-face.

with most of this group using a classmate's Blackboard Collaborate login credentials $(52 \%)$ and fewer watching archives with peers $(32 \%)$ or accessing them through a link $(21.3 \%)$. A small number of F2F students accessed archives through other unknown methods $(4 \%)$ and some declined to answer $(1.3 \%)$. A F2F student commented that it was necessary to "have friends in the online sections to get access to recordings from", suggesting that more F2F students may have used archives if they had an acquaintance in the online course. In contrast to lecture and laboratory archive sharing, very few online students $(5 \%)$ reported sharing access to Netter 3D Anatomy with a F2F classmate. Of these students, $60 \%$ provided their login credentials and $40 \%$ used the software with their colleagues. Only $5.5 \%$ of F2F students used the 3D models, all of whom declined to disclose how they accessed the software.

\section{Netter 3D Anatomy}

Approximately half of the online students (56\%) used Netter 3D Anatomy independent from the TAs. Helpfulness of the software's functions were rated on a five-point Likert scale such that a higher score indicated a higher level of helpfulness. Results are reported as mean \pm standard deviation. The functions with average ratings between quite helpful (4) and very helpful (5) were: adding labels to the models $(4.27 \pm 0.83)$, viewing body parts according to system (4.27 \pm 8.66 ), 
viewing body parts according to region (4.21 \pm 0.98$)$, dissecting models $(4.20 \pm 0.98)$, rotating models $(4.11 \pm 1.01)$, and magnifying models (4.02 \pm 1.07$)$. Functions averaging between somewhat helpful and quite helpful were: making body parts transparent $(3.96 \pm 0.93)$, adding body parts to the model $(3.65 \pm 1.19)$, and loading prepared dissections (.cap files) $(3.63 \pm 1.13)$.

The reasons why the remaining online students $(42.6 \%)$ did not use the software varied. The most frequent responses from approximately half the students were that they did not have time $(53.5 \%)$ and that they learned everything they needed to without the software $(51.2 \%)$. Additional reasons included the perception that it would not help them learn $(34.9 \%)$, the fact that it was not mandatory $(32.6 \%)$, an inability to launch it on their computers $(36.2 \%)$, the perception that it would not help with test preparation $(25.6 \%)$, a lack of interest in trying it $(16.3 \%)$, being unaware that they had access $(14 \%)$, having login credentials that did not work $(11.6 \%)$, and not knowing how to use it $(11.6 \%)$. Several online students $(n=14)$ shared the sentiment that Netter's 3D Anatomy did not use "real" images, which could account for the proportions of students that learned what they needed to without the software or did not think it would help them learn. One student articulated, "Netter's is animated and even though the program is great to learn the structures and their positions, it does not prepare you for how these structures really look like in the body". Another student shared, "it would also be nice to have $3 D$ models of cadaveric structures".

\section{DISCUSSION}

\section{Academic Performance}

The students' previous grades, and not course delivery format, predicted success in the anatomy course. This is consistent with outcomes of the preceding academic year (Attardi and Rogers, 2015) and findings from a similar study of online histology students at the same institution (Barbeau et al., 2013). In a meta-analysis of 103 studies, Lou et al. (2006) concluded that undergraduate students' academic performance is identical between student groups when instructors teach simultaneously and synchronously from a traditional classroom to remote sites using audio and/or videoconferencing technology. Lou et al.'s (2006) results can explain why the online students attending most sessions live could achieve the same outcomes as F2F students; however, the large majority of online student participants participated asynchronously. Studies have also shown that there are no differences in undergraduate student achievement when comparing synchronous to asynchronous distance formats (Bernard et al., 2009).

The only statistically significant difference between the sections was the online students' superior achievement on the first laboratory test. This may be attributed to the testing format. Laboratory test questions were pictures of cadavers and 3D models displayed on a screen at regular intervals, however, using physical specimens is a more traditional approach to testing the students' ability to identify anatomical structures (Inuwa et al., 2012). The discrepancy may be explained by the transfer of knowledge, which generally refers to the degree to which knowledge acquired in one context can be transferred to another (Barnett and Ceci, 2002). Online students were trained using 3D computer models and pictures on a computer screen, thus making it easier for them to interpret test questions in this format compared to F2F students who studied from physical specimens. This phenomenon has been observed in other anatomy education studies that compared academic achievement between student groups who had used different types of learning materials. Hisley et al. (2008) reported that students who performed real dissections scored lower on tests using 3D anatomical models than students who performed digital dissections on 3D models. Similar results, but in the reverse scenario, were observed by Saltarelli et al. (2014) when students learning from interactive digital cadaveric images were unable to transfer their knowledge to real cadavers. In the present study, F2F students were able to adapt to the testing format and achieve the same grades as online students on subsequent tests. Some of the F2F survey respondents suggested that they did not expect images of cadavers on their laboratory tests, so it is probable that they were underprepared for the first test but sought additional study resources when preparing for the remaining tests.

\section{Student-Teacher Interaction}

The majority of online students agreed that they were able to ask their teachers questions and could interact socially with them in both the lecture and laboratory settings. Students were able to instant message their teachers for any reason (academic, social) if they attended lecture and laboratories live. Interestingly, the archived versions of lectures and laboratories were preferred over live attendance. One of the most popular reasons noted in the literature for students favoring recorded lessons is the ability to control the instructional pace, and similar findings were reported in the previous year of the course (Attardi et al., 2016). The student's strong desire to control the delivery of information is not unique to the undergraduate level and has also been reported in studies on medical students' perceptions of learning from recorded lessons (Cardall et al., 2008; Wang et al., 2010; Beale et al., 2014; Singh and Min, 2017). Students may have perceived the benefit of pace control to be greater than the opportunity to interact live with their professors and TAs. They also may have benefitted from watching other students in the recording interact with the teacher. The small group of students who attended live had the ability to influence the course of the lesson through their questions and comments and this may have made the recording more engaging for asynchronous viewers.

It is unknown how students communicated socially or regarding academic matters with their teachers outside of live lecture and laboratory times, and future studies involving the online anatomy instructors are necessary to identify studentteacher communication methods. It is plausible that these communications were limited to F2F office hours, email, and the forum on the course website since the instructors did not permit students to contact them by text message or through social media (the primary means of student-student communication). The use of social media in medical education for student-teacher interactions is emerging (Cheston et al., 2013). Given that students used Facebook to communicate with their peers, the software could also provide a method for teachers to communicate with the students. Teachermoderated Facebook pages (Jaffar, 2013; Pickering and Bickerdike, 2017) and Twitter accounts (Hennessy et al., 2016) have been shown to be successful supplements to F2F anatomy instruction for medical students. 
When comparing the lecture to the laboratory sessions, more online and F2F students agreed that they could communicate socially with their teachers and were more engaged by them during the laboratory. This suggests that the way a learning environment (real or virtual) is used, and not the environment itself, influences student perception of communication and engagement with teachers. Compared to a traditional, didactic lecture, the laboratory demonstration setting allows for more conversation between students and teachers. Despite the fact that most online students viewed the laboratory demonstration as a recording, the instruction itself was less structured as the students attending live could interject and shape the flow of the lesson to decrease the transactional distance (Moore, 1989).

Since the majority of students agreed that they could interact with their TA for social and academic purposes and that they were engaged during the laboratory, the implementation of virtual breakout rooms and the team teaching approach by the TAs was successful. In 2012-2013, the overall reasons that students preferred the F2F laboratory format were that they were more engaged by the TAs and it was easier to ask them questions in person (Attardi et al., 2016). However, in the present study's comparisons of student-teacher communication between the online and F2F group in 2013-2014, a significantly greater proportion of F2F students agreed that that they could interact with their instructors. This may suggest that for some students, the online environment is not an adequate replacement for F2F in terms of communication.

\section{Student-Student Interaction}

The majority of online students agreed that they could ask questions of their peers and could interact socially with them in both the lecture and laboratory settings. Since most online students did not attend lectures and laboratories during live times, it can be inferred from the data that their primary means of communication with peers pertaining to the study of anatomy were texting from a mobile device, Facebook, and meeting face-to-face. It is unknown if social interaction was included in these communications. Despite the intention for the forum on the course website to be a primary means of communication between students, most respondents in both sections reported that they used it rarely or never. The communication tool used most frequently was texting from a mobile device. In the year that this study took place, more undergraduate students in the United States owned mobile devices than ever before, with $86 \%$ owning a smart phone specifically (Dahlstrom and Bichsel, 2014). Since students expect access to course materials any time and from anywhere (Dahlstrom et al., 2013), it is reasonable to infer that they value timely communication with peers regarding course content. The forum on the anatomy course website was not conducive to prompt responses since students were unable to receive alerts from a specific thread in the discussion. It is possible that the students did not use the course website due to its functional deficits, and not for the reason that they opposed using a learning management system. Other studies of anatomy students have shown greater forum activity and associated its use with higher grades (Green and Hughes, 2013; Green et al., 2014). Undergraduate students seek to increase the use of their personal digital devices for learning outside of the classroom (Dahlstrom et al., 2013). They recognize the learning management system as a key tool in their student experience and want it to be mobile-friendly and personalized (Dahlstrom and Bichsel, 2014).

Approximately one third of the online students reported that they communicated about the course with peers by meeting $\mathrm{F} 2 \mathrm{~F}$ and described the frequency of the meetings as "moderate" or "a great deal". By definition, online courses do not require F2F meetings (Bates, 2005), but it is interesting that a substantial proportion of online students sought these encounters. Face-to-face meetings were possible because all of the online students were registered in campus-based degree programs. It is important to note that this finding might not translate to courses taken by distance studies students who are located remotely and are not required to visit campus.

More F2F students had access to archives than the number of online students who reported sharing their access to the recorded lectures and laboratories. This suggests that resource sharing was exponential such that an online student may have provided their login credentials to more than one F2F peer, who in turn could have shared the same credentials with more than one person. Likewise, viewing archives could have occurred in groups. Most F2F students reported that they used a peer's login credentials. This method of sharing was likely the easiest since it did not require students to coordinate meeting F2F. Viewing the archives individually would also allow the user to adjust for pace and review specific parts of the recording according to personal need. The current study's findings present the issue of ethical software use. Contracts for institutional software licenses will commonly specify a number of authorized users, and individual accounts are not intended to be accessed by multiple students. When software has been purchased for a specific course, instructors should consider including the terms for use in the syllabus or require students to sign a user agreement.

The F2F students' desire to view archived materials supports Dahlstrom and Bichel's (2014) finding that lecture capture is the premier technology that undergraduate students want their instructors to use more. It is common in studies of online anatomy learning resources to draw conclusions about student usage solely from access logs (Bacro et al., 2010; McNulty et al., 2011; Nieder and Borges, 2012). The present study illustrates why logs alone may not provide an accurate representation of student usage and that it is also necessary for students to self-report as exemplified in other studies (McNulty et al., 2009, Bacro et al., 2013; Gupta and Saks, 2013; Topping, 2014).

\section{Netter 3D Anatomy}

In the first study of the online course, survey respondents assessed the helpfulness of the same Netter 3D Anatomy functions (Attardi et al., 2016). The top rated function (adding labels to body parts) was identified as helpful by only $59.3 \%$ of students, and overall ratings for each function were lower than in the second course offering. It should be noted that these survey respondents were F2F students who only attended the course online for one week, which included access to the $3 \mathrm{D}$ models. In the current study, respondents were students enrolled in the online section for two semesters. Their most favored functions (dissecting models, adding labels, and viewing body parts by region) were each rated as helpful by more than $70 \%$ of students. Comparison between the years suggests that increased time available for students 
to use the software and the modifications to the online course (additional training and technical support from the TAs, interactive drawing exercises with the $3 \mathrm{D}$ models) were successful in facilitating a more meaningful use of 3D models.

Of the 43 students who did not use the 3D models, approximately half perceived that they learned everything they needed to without it. Since performance on laboratory assessments was not linked to survey responses, it is unknown if grades were correlative to $3 \mathrm{D}$ model use. Fifteen students perceived that the software would not help them learn. Azer and Azer's (2016) review of 30 studies on the impact of 3D anatomy models revealed that students favor using 3D models (computed based or physical) over textbook and lectures, but 3D model use does not necessarily enhance students' anatomy performance. Student learning can be affected by the design of the tool, how it is implemented in the curriculum, and both innate and acquired learner characteristics (Azer and Azer, 2016; Van Nuland and Rogers, 2016, 2017). Fourteen students did not use Netter 3D Anatomy because they could not launch it on their computers. The local (downloaded) version of the software, which allows users to share prepared 3D models (.cap files), could only be installed on computers with a Windows (Microscoft Corp., Redmond, WA) operating system. It is likely that these nonusers had MacIntosh (Apple Inc., Cupertino, CA) computers. Though Windows operating systems dominated the undergraduate student market share for laptops (64\%) and desktops $(81 \%)$, almost all the remaining share was held by MacIntosh operating systems (Dahlstrom at al., 2015). Interestingly, the downloaded version of the software was available on Windows computers in an on-campus computer laboratory; however, these students chose not to use the product because they could not launch it on their own computers. An online student survey respondent explained, "I didn't get to use Netter's as my computer is a Mac and the software didn't work. I would have to go into the lab to use Netters which was not very convenient".

\section{Optional Face-to-Face Laboratory Time for Online Students}

Online student presence at optional F2F laboratory time was not reported since attendance was not recorded. However, it was the course coordinator's impression that the sessions were poorly attended as fewer than five students attended weekly and they were the same students. An online student survey respondent explained that it was not possible to visit the laboratory due to a scheduling conflict with a mandatory lecture in his/her program (Honours Bachelor of Medical Science). Conversely, the laboratory test review sessions were well attended with approximately 30-50 students (combined online and F2F) attending for some part of the session time. Few students stayed for the entire three hours. The students were very grateful for the extra opportunity to review this material with the prosections.

\section{Study Limitations}

This study examined a new course with a novel approach to delivery. It was exploratory in nature and examined many phenomena to ensure that important outcomes were not overlooked. In the interest of limiting the survey to a desirable length for participants, it was not feasible to include detailed and numerous items for each phenomena (e.g., engagement, interaction, communication methods). Secondly, it is unknown whether there are relationships between the students' academic performance and survey responses. The large dataset was analyzed only according to enrollment in the online or F2F section. It was not possible to stratify data according to the students' performance or other variables since personal identifiers were intentionally not stored with survey data. Anonymous surveys likely increased validity of the findings, but at the expense being unable to detect response patterns according to performance demographics. Finally, the study's strength was that it involved an official course and reflected real student behaviors; however, this limited the researchers' ability to strictly maintain the integrity of the experimental groups. Randomization was not possible because students self-enrolled in one of the sections through the university registrar. It is unknown why students selected a particular section, suggesting that there may be unknown confounding variables particular to one of the groups. The groups did not remain completely separated through the course of the study, as students reported the sharing of online resources with F2F students, which may have affected the F2F students' performance. It is less likely to have influenced survey responses because the students were instructed to rate experiences from their official course section.

\section{Future Directions}

This research and previous work (Attardi and Rogers, 2015; Attardi et al., 2016) have assessed student outcomes and perception of the online course over a two year period in comparison to its F2F counterpart. These types of studies are often criticized in the literature, as some claim they serve to prove that one format is as good as the other but do not advance pedagogical practices in either format (LarreamendyJoerns and Leinhardt, 2006; Bernard et al., 2009; Cook, 2009). In the infancy of the course, where online students learned in a different format for the first time, yet received the same credit as F2F students, there was an obligation to compare the sections. Moving forward, comparison of variations of the online format will provide a better way of observing the effects of instructional interventions (Cook et al., 2008; Bernard et al., 2009). As major themes emerged surrounding student-instructor interaction and student-content interaction (i.e., lack of a general consensus for the usefulness of Netter 3D Anatomy), future studies should examine the effects of different online interaction methods and anatomical software.

The data were analyzed by grouping participants according to course delivery format. The resulting sample sizes were large and it is expected that there were many variations between individuals in each group. In future studies, variance can be reduced further if additional demographic data are collecting during the survey or linked to student performance data. The survey respondents' incoming grade average, final anatomy grades, communication habits, and reasons for selecting a specific delivery format remain independent variables of interest.

Studies of the first two years of Systemic Human Anatomy Online have focused on student outcomes and perspectives. Future qualitative studies will reveal professor and teaching assistant perspectives of teaching anatomy online during this same period (2012-2014). 


\section{CONCLUSIONS}

Online virtual laboratory breakout rooms exposed students to three TAs each week and allowed them to learn in smaller groups. The new laboratory format facilitated the online students' use of Netter 3D Anatomy. The majority of online students perceived that they could ask their professors, TAs, and peers questions about the course and interact socially with them. Few of these interactions, however, occurred within the virtual classroom during live lecture and laboratory times. The students' preferred methods of interacting with their peers was through texting from a mobile device, Facebook, and meeting F2F. It is unknown how they interacted with their professors outside of class. While use of virtual breakout rooms engaged online students in learning and the students were satisfied with their interactions with TAs and peers, online laboratories do not appear to adequately replace the F2F learning environment for all students. Consistent with the previous year, performance in anatomy was predicted by prior academic achievement, and not the course format.

\section{ACKNOWLEDGMENTS}

The authors wish to acknowledge Systemic Human Anatomy professors Drs. Peter Merrifield, David Cechetto, and Steven Laviolette, and teaching assistants Dr. Sonya Van Nuland, Leah Labranche, Sarah Fitzpatrick, and Nicolle Clements for their dedication to teaching the online section of the course. They are grateful for technology support from Jane Winkler (The University of Western Ontario's Instructional Technology Resource Centre) and Michael Wu. They thank Joan Estabrooks and Michael Wu for providing student grade data. They are grateful for the anatomy students' participation in the survey and for support from The University of Western Ontario's Science Students' Council. They also thank Daniel Gildner for statistical consultation (Department of Psychology, Oakland University).

\section{NOTES ON CONTRIBUTORS}

STEFANIE M. ATTARDI, Ph.D., is an assistant professor in the Department of Biomedical Sciences at Oakland University William Beaumont School of Medicine, Rochester, Michigan. She teaches histology and gross anatomy to medical students and her research interest is medical education. She received her doctorate from the Department of Anatomy and Cell Biology at The University of Western Ontario, London, Canada.

MICHELE L. BARBEAU, Ph.D., is an instructor in the Department of Anatomy and Cell Biology, Schulich School of Medicine and Dentistry at The University of Western Ontario, London, Canada. She teaches histology and gross anatomy to professional and undergraduate biological science students and her research interest is in online education.

KEM A. ROGERS, Ph.D., is a professor in the Department of Anatomy and Cell Biology, Schulich School of Medicine and Dentistry at The University of Western Ontario, London, Canada. His research interests range from models of cardiovascular disease to educational scholarship.

\section{LITERATURE CITED}

Acland RD. 2013. Acland's Video Atlas of Human Anatomy. Woulters Kluwver Health/Lippincott, William \& Wilkins, Baltimore, MD. URL: www.aclandanatomy.com [accessed 3 August 2017].
ADAM. 2017. A.D.A.M. Interactive Anatomy. Ebix Inc., Atlanta, GA. URL: http://www.adameducation.com/ [accessed 3 August 2017].

Attardi SM, Choi S, Barnett J, Rogers KA. 2016. Mixed methods student evaluation of an online systemic human anatomy course with laboratory. Anat Sci Educ 9:272-285.

Attardi SM, Rogers KA. 2015. Design and implementation of an online systemic human anatomy course with laboratory. Anat Sci Educ 8:53-62.

Azer SA, Azer S. 2016. 3D anatomy models and impact on learning: A review of the quality of the literature. Health Prof Educ 2:80-98.

Aziz MA, McKenzie JC, Wilson JS, Cowie RJ, Ayeni SA, Dunn BK. 2002. The human cadaver in the age of biomedical informatics. Anat Rec 269B:20-32.

Bacro TR, Gebregziabher M, Ariail J. 2013. Lecture recording system in anatomy. Anat Sci Educ 6:376-384.

Bacro TR, Gebregziabher M, Fitzharris TP. 2010. Evaluation of a lecture recording system in a medical curriculum. Anat Sci Educ 3:300-308.

Barbeau ML, Johnson M, Gibson C, Rogers KA. 2013. The development and assessment of an online microscopic anatomy laboratory course. Anat Sci Educ 6:246-256.

Barnett SM, Ceci SJ. 2002. When and where do we apply what we learn? A taxonomy for far transfer. Psychol Bull 4:612-637.

Bates AW. 2005. Technology, E-Learning and Distance Education. 2nd Ed. New York, NY: Routledge. 246 p.

Beale EG, Tarwater PM, Lee VH. 2014. A retrospective look at replacing faceto-face embryology instruction with online lectures in a human anatomy course. Anat Sci Educ 7:234-241.

Bernard RM, Abrami PC, Borokhovski E, Wade CA, Tamim RM, Surkes MA, Bethel EC. 2009. A meta-analysis of three types of interaction treatments in distance education. Rev Educ Res 79:1243-1289.

Boudinot SG, Martin BC. 2001. Online anatomy lab (OAL): A self-regulated approach to the instruction of human anatomy. Interact Multimed Electron J Comput Enhanc Learn 3:1.

Bunton SA. 2016. Using qualitative research as a means to an effective survey instrument. Acad Med 91:1183.

Cardall S, Krupat E, Ulrich M. 2008. Live lecture versus video-recorded lecture: Are students voting with their feet? Acad Med 83:1174-1178.

Chan D. 2009. So why ask me? Are self-report data really that bad? In: Lance C, Vandenberg R (Editors). Statistical and Methodology Myths and Urban Legends: Doctrine, Verity and Fable in Organizational and Social Sciences. 1st Ed. New York, NY: Routledge. p 309-336.

Cheston CC, Flickinger T, Chisolm MS. 2013. Social media use in medical education: A systematic review. Acad Med 88:893-901.

Choudhury B, Gouldsborough I. 2012. The use of electronic media to develop transferable skills in science students studying anatomy. Anat Sci Educ 5:125-131. Collins JP. 2008. Modern approaches to teaching and learning anatomy. BMJ 227:a1310.

Cook DA. 2009. The failure of e-learning research to inform educational practice, and what we can do about it. Med Teach 31:158-162.

Cook DA, Levinson AJ, Garside S, Dupras DM, Erwin P, Montori VM. 2008. Internet-based learning in the health professions. A meta-analysis. JAMA 300: 1181-1196.

CVU-UVC. 2016. Canadian Virtual University - L'Université Virtuelle Canadienne. Anatomy. CVU-UVC ${ }^{\circledR}$, Athabasca, AB, Canada. URL: http://www.cvuuvc.ca/search.php ?language $=$ English \&q $=$ anatomy \& type $=$ courses $[$ accessed 3 August 2017].

Dahlstrom E, Bichsel J. 2014. ECAR Study of undergraduate students and information technology, 2014. 1st Ed. Louisville, CO: EDUCASE Center for Analysis and Research. 50 p. URL: http://net.educause.edu/ir/library/pdf/ss14/ ERS1406.pdf [accessed 3 August 2017].

Dahlstrom E, Brooks C, Grajek S, Reeves J. 2015. ECAR study of students and information technology, 2015. 1st Ed. Louisville, CO: EDUCAUSE Center for Analysis and Research. 47 p. URL: https://library.educause.edu/resources/2015/8/ / media/24ddc1aa35a5490389baf28b6ddb3693.ashx [accessed 3 August 2017].

Dahlstrom E, Walker JD, Dziuban C. 2013. ECAR study of undergraduate students and information technology 2013. 1st Ed. Louisville, CO: Educause Centre for Analysis and Research. 49 p. URL: https://net.educause.edu/ir/library/ pdf/ERS1302/ERS1302.pdf [accessed 3 August 2017].

Doubleday EG, O'Loughlin VD, Doubleday AF. 2011. The virtual anatomy laboratory: Usability testing to improve an online learning resource for anatomy education. Anat Sci Educ 4:318-326.

Durham JA, Brettell S, Summerside C, McHanwell S. 2009. Evaluation of a virtual anatomy course for clinical undergraduates. Eur J Dent Educ 13: 100-109.

Dyer GS, Thorndike ME. 2000. Quidne mortui vivos docent? The evolving purpose of human dissection in medical education. Acad Med 74:969-979.

Green RA, Farchione D, Hughes DL, Chan SP. 2014. Participation in asynchronous online discussion forums does improve student learning of gross anatomy. Anat Sci Educ 7:71-76.

Green RA, Hughes DL. 2013. Student outcomes associated with use of asynchronous online discussion forums in gross anatomy teaching. Anat Sci Educ 6:101-106. 
Green SM, Weaver M, Voegeli D, Fitzsimmons D, Knowles J, Harrison M, Shephard K. 2006. The development and evaluation of the use of a virtual learning environment (Blackboard 5) to support the learning of pre-qualifying nursing students undertaking a human anatomy and physiology module. Nurse Educ Today 26:388-395.

Gunderman RB, Wilson PK. 2005. Exploring the human interior: The roles of cadaver dissection and radiologic imaging in teaching anatomy. Acad Med 80: $745-749$.

Gupta A, Saks NS. 2013. Exploring medical student decisions regarding attending live lectures and using recorded lectures. Med Teach 35:767-771.

Guy R, Pisani HR, Rich P, Leahy C, Mandarano G, Molyneux T. 2015. Less is more: Development and evaluation of an interactive e-atlas to support anatomy learning. Anat Sci Educ 8:126-132.

Hennessy CM, Kirkpatrick E, Smith CF, Border S. 2016. Social media and anatomy education: Using twitter to enhance the student learning experience in anatomy. Anat Sci Educ 9:505-515.

Hisley KC, Anderson LD, Smith SE, Kavic SM, Tracy JK. 2008. Coupled physical and digital cadaver dissection followed by a visual test protocol provides insights into the nature of anatomical knowledge and its evaluation. Anat Sci Educ 1:27-40.

Inuwa IM, Taranikanti V, Al-Rawahy M, Habbal O. 2012. Anatomy practical examinations: How does student performance on computerized evaluation compare with the traditional format? Anat Sci Educ 5:27-32.

Jaffar AA. 2013. Exploring the use of a Facebook page in anatomy education. Anat Sci Educ 7:199-208.

Larreamendy-Joerns J, Leinhardt G. 2006. Going the distance with online education. Rev Educ Res 76:567-605.

Limpach AL, Bazrafshan P, Turner PD, Monaghan MS. 2008. Effectiveness of human anatomy education for pharmacy students via the Internet. Am J Pharm Educ $72: 145$.

Lou Y, Bernard RM, Abrami PC. 2006. Media and pedagogy in undergraduate distance education: A theory-based meta-analysis of empirical literature. Educ Tech Res Dev 54:141-176.

Mathiowetz V, Yu C, Quake-Rapp C. 2016. Comparison of a gross anatomy laboratory to online anatomy software for teaching anatomy. Anat Sci Educ 9: 52-59.

McLachlan JC, Bligh J, Bradley P, Searle J. 2004. Teaching anatomy without cadavers. Med Educ 38:418-424

McLachlan JC, Patten D. 2006. Anatomy teaching: Ghosts of the past, present, and future. Med Educ 40:243-253.

McNulty JA, Hoyt A, Chandrasekhar AJ, Espiritu B, Gruener G, Price R, Naheedy R. 2011. A three-year study of lecture multimedia utilization in the medical curriculum: Associations with performance in basic sciences. Med Sci Educ 1:29-36.

McNulty JA, Hoyt A, Gruener G, Chandrasekhar A, Espiritu B, Price R, Naheedy R. 2009. An analysis of lecture video utilization in undergraduate medical education: Associations with performance in the courses. BMC Med Educ 9:6.

Moore MG. 1989. Three types of interaction. Am J Dist Educ 3:1-7.

Moore MG. 1993. Theory of transactional distance. In: Keegan D (Editor). Theoretical Principles of Distance Education. 1st Ed. Abingdon, Oxon, UK Routledge. p 22-38.

Netter FH. 2014. Netter 3D Anatomy. Elsevier, Philadelphia, PA. URL: http://netter3danatomy.com [accessed 3 August 2017].

Nieder GL, Borges NJ. 2012. An eight year study of online lecture use in a medical gross anatomy and embryology course. Anat Sci Educ 5:311-320.
O'Byrne PJ, Patry A, Carnegie JA. 2008. The development of interactive online learning tools for the study of anatomy. Med Teach 30:e260-e271.

Persaud TV. 1984. The Early History of Anatomy: From Antiquity to the Beginning of the Modern Era. 1st Ed. Springfield IL: Thomas Books. 357 p.

Pickering JD, Bickerdike SR. 2017. Medical student use of Facebook to support preparation for anatomy assessments. Anat Sci Educ 10:205-214.

Pickering JD, Swinnerton BJ. 2017. An anatomy massive open online course as a continuing professional development tool for healthcare professionals. Med Sci Educ 27:243-252.

Raynor M, Iggulden H. 2008. Online anatomy and physiology: Piloting the use of an anatomy and physiology e-book-VLE hybrid in pre-registration and post-qualifying nursing programmes at the University of Salford. Health Info Libr J 25:98-105.

Saldaña J. 2016. The Coding Manual for Qualitative Researchers. 3rd Ed. Thousand Oakls, CA: SAGE Publications Inc. 368 p.

Saltarelli AJ, Roseth CJ, Saltarelli WA. 2014. Human cadaver vs multimedia simulation: A study of student learning in anatomy. Anat Sci Educ 7:331-339.

SDNL. 2012. Self-Directed Neuroanatomy Laboratory. Schulich School of Medicine and Dentistry, The University of Western Ontario, London, Canada. URL: http://360anatomy.uwo.ca/ [accessed 3 August 2017].

Simonson M, Schlosser C, Ornella A. 2011. Distance education research: A review of the literature. J Comput Higher Educ 23:124-142.

Singh A, Min AK. 2017. Digital lectures for learning gross anatomy: A study of their efficacy. Kor J Med Educ 29:27-32.

Spitzer V, Ackerman MJ, Scherzinger AL, Whitlock D. 1996. The visible human male: A technical report. J Am Med Inform Assoc 3:118-130.

Study.com. 2017. Online anatomy course overviews with school options. Study.com, Mountain View, CA. URL: http://study.com/online_anatomy_ course.html [accessed 22 May 2017].

Sugand K, Abrahams P, Khurana A. 2010. The anatomy of anatomy: A review for its modernization. Anat Sci Educ 3:83-93.

Swinnerton BJ, Morris NP, Hotchkiss S, Pickering JD. 2017. The integration of an anatomy massive open online course (MOOC) into a medical anatomy curriculum. Anat Sci Educ 10:53-67.

Tallitsch RB, Abdel-Malek K, Krippel J, Beck A, Croll P, Fenwick S, Kelley K, Peters B. 2012. Computer-assisted instruction increased students' ability to interpret 3D relationships and retain essential material in undergraduate human anatomy and A\&P courses. FASEB J 26:S530.10.

Trelease RB. 2002. Anatomical informatics: Millennial perspectives on a newer frontier. Anat Rec 269:224-235.

Trelease RB. 2016. From chalkboard, slides, and paper to e-learning: How computing technologies have transformed anatomical sciences education. Anat Sci Educ 9:583-602.

Topping DB. 2014. Gross anatomy videos: Student satisfaction, usage, and effect on student performance in a condensed curriculum. Anat Sci Educ 7: 273-279.

Van Nuland SE, Rogers KA. 2016. The anatomy of e-learning tools: Does software usability influence learning outcomes? Anat Sci Educ 9:378-390.

Van Nuland SE, Rogers KA. 2017. The skeletons in our closet: E-learning tools and what happens when one side does not fit all. Anat Sci Educ 10: 570-588.

Wang RL, Mattick K, Dunne E. 2010. Medical students' perceptions of videolinked lectures and video streaming. Res Learn Tech 18:19-27.

Wright SJ. 2012. Student perceptions of an upper level undergraduate human anatomy laboratory course without cadavers. Anat Sci Educ 5:146-157. 